\title{
Radiological CT Patterns and Distribution of Invasive Pulmonary Aspergillus, Non-Aspergillus, Cryptococcus and Pneumocystis Jirovecii Mold Infections - A Multicenter Study
}

\author{
Radiologische Muster und Verteilung in der CT bei invasiven \\ pulmonalen Aspergillus-, Nicht-Aspergillus-, Kryptokokken- \\ und Pneumocystis-jiroveci-Pilzinfektionen - eine Multicenterstudie
}

Authors

Verena C. Obmann ${ }^{1}$, Flurina Bickel ${ }^{1}$, Nicola Hosek ${ }^{1}$, Lukas Ebner ${ }^{1}$, Adrian T. Huber ${ }^{1}$, Lauro Damonti ${ }^{2}$, Stefan Zimmerli², Andreas Christe ${ }^{1}$

Affiliations

1 Department of Interventional, Pediatric and Diagnostic Radiology, Inselspital, University of Bern, Switzerland

2 Department of Infectious Diseases, Inselspital, University of Bern, Switzerland

Key words

ultrasound computed tomography (US/CT), x-ray, invasive fungal infections, chest, pneumonia

received 01.10 .2020

accepted 05.04.2021

published online 25.05.2021

Bibliography

Fortschr Röntgenstr 2021; 193: 1304-1314

DOI $10.1055 / a-1482-8336$

ISSN 1438-9029

(c) 2021. Thieme. All rights reserved.

Georg Thieme Verlag KG, Rüdigerstraße 14,

70469 Stuttgart, Germany

Correspondence

Dr. Verena C. Obmann

University Institute of Diagnostic, Interventional and Pediatric

Radiology, Inselspital - University Hospital Bern,

Freiburgstr. 10, 3008 Bern, Switzerland

Tel.: $+41 / 31 / 6322435$

Fax: $+41 / 31 / 6324874$

Verena.Obmann@insel.ch

$\circledast$

Supplementary material is available under

https://doi.org/10.1055/a-1482-8336

\section{ZUSAMMENFASSUNG}

Ziel Systematische Analyse der CT-Muster bei invasiven pulmonalen Pilzinfektionen in Abhängigkeit vom Immunstatus und dem klinischen Outcome der Patienten.

Material und Methoden In dieser retrospektiven Multicenterstudie wurden 85 konsekutive Patienten mit invasiver pulmonaler Pilzinfektion eingeschlossen (2011-2014). Die CT-Muster der Lunge wurden gemäß dem Glossar der Fleischner-Society klassifiziert. Die Patienten wurden nach Immunstatus (Neutropenie, Steroidtherapie, Organtransplantation und andere Ursachen) und Outcome (positiver Verlauf, progrediente Erkrankung und Tod) unterteilt. Der Chi-Quadratund der Fischer-Exact-Test wurden mit der Bonferroni-Korrektur angewandt.

Ergebnisse Die Anzahl der Patienten mit invasiver Aspergillus- und Nicht-Aspergillus-Infektion (IANA), Pneumocystisjirovecii-Pneumonie (PCP) und Kryptokokken (CRY) betrug jeweils 60, 22 und 3. Die IANA-Patienten wiesen signifikant häufiger Lungenknoten ( $93 \%$ vs. $59 \%$; $p=0,001$ ), signifikant weniger Milchglastrübungen ( $58 \%$ vs. $96 \%$; $p=0,005$ ) und signifikant weniger pathologische Lymphknoten auf ( $5 \%$ vs. $41 \%$; $<0,001)$ als Patienten mit PCP. Alle Patienten mit PCP und CRY zeigten einen positiven Verlauf. Bei IANA-Patienten waren Knoten mit Halo-Zeichen häufiger assoziiert mit negativem (Progress, Tod) als mit positivem Verlauf (42,5\% vs. $15,9 \% ; p<0,0001)$. Interessanterweise zeigten Patienten mit positivem Verlauf häufiger Lungeninfarkte als Patienten mit negativem Verlauf ( $8 \%$ vs. $1 \%$; $p=0,047$ ). Patienten mit Neutropenie litten signifikant mehr an Lungeninfiltraten (Konsolidierungen, $66 \%$ ) als Patienten nach Organtransplantation $(27 \% ; p=0,045)$.

Schlussfolgerung IANA-Patienten zeigten eine höhere Prävalenz von Lungenknoten und eine tiefere Prävalenz von Milchglastrübungen im Vergleich zu PCP-Patienten. Bei den IANA-Patienten waren die Noduli mit Halo-Zeichen mit einem schlechteren Verlauf assoziiert. Patienten mit Neutropenie zeigten generell mehr Infiltrate, diese waren allerdings nicht mit negativem Verlauf assoziiert.

\section{Kernaussagen:}

- Lungenknoten, Milchglastrübungen und Konsolidierungen sind häufige CT-Zeichen bei allen invasiven pulmonalen Pilzinfektionen.

- Es gibt kein CT-Muster, das einzigartig ist für einen bestimmten Erreger, obwohl Lungenknoten häufiger bei 
IANA und Kryptokokken vorkommen und Milchglastrübungen häufiger bei PCP-Infektionen zu beobachten sind.

- Der Immunstatus der Patienten beeinflusst die CT-Befunde der Pilz-Pneumonie: Patienten zeigten nach Organtransplantation weniger Konsolidierungen als Patienten mit Neutropenie.

- Noduli mit Halo-Zeichen sind mit einem schlechteren Outcome assoziiert.

\section{ABSTRACT}

Purpose Clinical signs and symptoms related to invasive fungal disease are nonspecific and need to be followed up by appropriate diagnostic procedures. The goal of this study was to analyze CT imaging patterns in invasive fungal infections and their correlation with the immune status and clinical outcome.

Materials and Methods We performed a retrospective multicenter study including 85 consecutive patients with invasive pulmonary fungal infection (2011-2014). Lung patterns on computed tomography (CT) scans were classified according to the Fleischner Society glossary. The patients were grouped according to immune status (neutropenia, steroid therapy, organ transplant recipient, and other cause) and outcome (positive outcome, progressive disease, and death). The Chi square test or Fisher exact test was used. Bonferroni correction was applied.

Results The total number of patients with invasive Aspergillus and non-Aspergillus infection (IANA), Pneumocystis jirovecii pneumonia (PCP), and Cryptococcus (CRY) was 60, 22, and 3 , respectively. Patients with IANA demonstrated significantly more nodules ( $93 \%$ vs. $59 \%, p=0.001$ ), significantly fewer ground glass opacities ( $58 \%$ vs. $96 \%, p=0.005$ ), and significantly fewer positive lymph nodes (5\% vs. $41 \%, p<0.001$ ) than patients with PCP. All patients with PCP and CRY had a favorable outcome. Patients with IANA and an adverse out- come demonstrated significantly more nodules with halo sign than patients with IANA and a favorable outcome (42.5\% vs. $15.9 \%, p<0.0001)$. Interestingly, patients with IANA and a favorable outcome had a higher prevalence of pulmonary infarction than patients with an adverse outcome $(8 \%$ vs. $1 \%, p=0.047)$. Patients with neutropenia showed significantly more consolidations (66\%) than organ transplant recipients $(27 \%, \mathrm{p}=0.045)$.

Conclusion Patients with IANA showed a higher prevalence of nodules and a lower prevalence of ground glass opacities than patients with PCP. In patients with IANA, nodules with halo sign were associated with an adverse outcome. Patients with neutropenia showed generally more consolidations, but the consolidations were not associated with an adverse outcome.

\section{Key Points:}

- Nodules, ground glass opacities, and consolidations are common CT findings in all invasive pulmonary fungal infections.

- There is no pattern that is unique for one specific pathogen, although nodules are more predominant in IANA and Cryptococcus, and ground glass opacities are more predominant in PCP patients.

- Immune status had an impact on CT findings in fungal pneumonia with less consolidation in patients after organ transplantation compared to patients with neutropenia.

- Nodules with a halo sign are associated with a worse outcome.

\section{Citation Format}

- Obmann VC, Bickel F, Hosek N et al. Radiological CT Patterns and Distribution of Invasive Pulmonary Aspergillus, Non-Aspergillus, Cryptococcus and Pneumocystis Jirovecii Mold Infections - A Multicenter Study. Fortschr Röntgenstr 2021; 193: 1304-1314

\section{Introduction}

Opportunistic fungal infections of the lung are a common complication in immunocompromised patients and are related to a high morbidity and mortality [1, 2]. Therefore, early and accurate diagnosis of invasive fungal infection (IFI) is important to improve patient survival $[3,4]$. When neutropenia lasts more than 7 days, fungal infections may occur (aspergillosis, candidiasis, mucormycosis) [5-7]. The clinical diagnosis of fungal pulmonary infection is based on host factors (i. e., immune status, neutropenic fever), clinical signs (unexplained fever despite broad-spectrum antibiotics), microbiological evidence of infection, and specific patterns on computed tomography (CT) imaging [1, 8-10]. Clinical signs and symptoms related to IFI (i. e. cough, pleural pain, or hemoptysis) are nonspecific and need to be followed up by appropriate diagnostic procedures as part of an integrated care pathway consisting of daily physical examination, microscopy, and mycological culture of all samples, serum, and bronchoalveolar lavage (BAL),
Galactomannan (GAL) antigen assay, serum (1-3)- $\beta$-D-Glucan (BDG), and high-resolution CT (HRCT) [11-14]. CT plays an important role in the diagnosis and management of patients with pulmonary fungal infections due to its ability to depict disease at an early stage [15].

Chest CT has provided important clues regarding the clinical suspicion and early treatment of invasive mold pneumonia in immunocompromised patients [16]. CT findings in fungal infections such as multiple nodules, ground glass opacities, and (reverse) halo sign are due to parenchymal invasion of the fungus hyphae and/or parenchymal infarctions due to invasion of the pulmonary vessels and are thus seen earlier [15]. Legouge et al. reported that the reverse halo sign was present in 15 (94\%) of 16 patients with pulmonary mucormycosis during the first week of the disease, and the authors proposed that the reverse halo sign could be a sensitive sign for pulmonary mucormycosis, especially early in the disease [17]. However, this could not be confirmed by other authors, making the reverse halo sign relatively nonspecific [18]. 


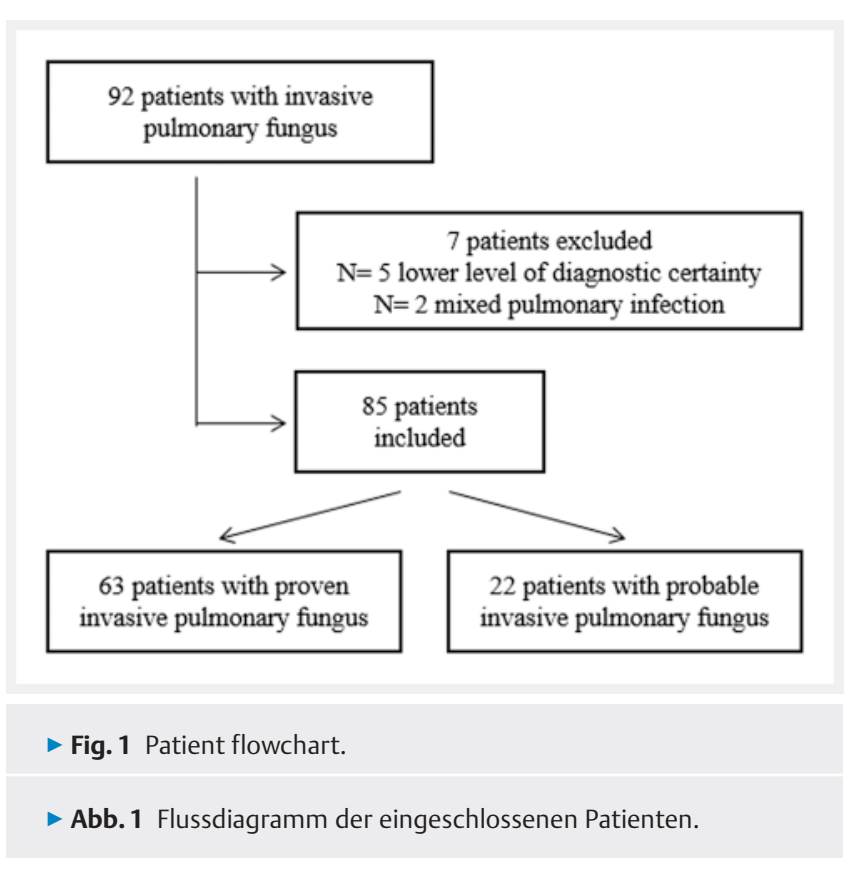

The aim of this study was 1) the systematic CT pattern mapping of all invasive fungal infections of the lung in a current consecutive cohort, 2) the depiction of predictive CT findings associated with a positive (regression) or negative outcome (progression or death), 3) to assess the influence of the immune status of patients (neutropenia, high-dose steroid therapy, organ transplant, other) and the infective agent on the $\mathrm{CT}$ patterns.

\section{Materials and Methods}

\section{Patient population}

Chest CT images of 92 consecutive patients with invasive fungal infection were included in this retrospective multicenter study. Informed consent was waived due to the retrospective nature of the study. All adult patients at the three institutions (tertiary referral hospitals) who met the criteria for mold infection - Aspergillosis (IPA, Invasive Pulmonary Aspergillus), non-Aspergillus invasive mold infection (NAIMI, such as Mucormycosis agents), Cryptococcosis (CRY) - according to the 2008 EORTC/MSG criteria as well as patients with Pneumocystis jirovecii Pneumonia (PCP) (proven with immunofluorescence only) were enrolled [10].

The inclusion criteria were a proven or probable fungal infection and a chest $\mathrm{CT}$ within one week of the date of diagnosis. We excluded patients with a lower level of diagnostic certainty (possible infection) and those with mixed pulmonary infections (i. e., bacterial or viral co-infections) from our analysis. 85 patients met the criteria ( $\triangleright$ Fig. 1): 39, 33, and 13 patients were recruited at centers 1, 2, and 3 , respectively. 63 patients with proven invasive pulmonary fungus and 22 with probable invasive pulmonary fungus were included.

The study population was categorized by type of fungal infection, and four subgroups depending on immune status were built: 1) Neutropenia: neutropenia at the time of $C T$ examination regardless of underlying disease $(n=44)$. Etiologies for neutropenia were acute myeloid leukemia (AML) $(n=14)$, chronic lymphocytic leuke- mia $(C L L)(n=8)$, non-Hodgkin's lymphoma (NHL) $(n=5)$, acute lymphocytic leukemia (ALL) $(n=4)$, chemotherapy, and other rare disease like multiple myeloma, plasmacytoma, and Hodgkin's disease ( $n=13)$. 2) High-dose steroid therapy applied in cases of malignancies, organ transplant, and different rheumatologic or autoimmune diseases $(n=36)$. 3) Organ transplant recipients (OTR) ( $n=11$, with $n=7$ kidney and $n=4$ lung transplant). 4) All other underlying diseases not fitting into one of the previous categories suffering from invasive fungal pneumonia such as HIV infection $(n=3)$, malignancy $(n=1)$, COPD $(n=5)$, tuberculosis infection $(n=1)$, and autoimmune disease $(n=2)$. If a patient matched two immune status groups, the pulmonary findings counted in both groups.

Patients with IANA infection were subdivided into the 4 clinical outcome groups: 1) 29 with positive outcomes, 2) 4 with progressive disease, 3) 14 with death due to other causes and 4) 6 with death due to infection; the remaining 7 patients were lost to follow-up.

\section{Imaging acquisition and interpretation}

Chest CT studies at the time of initial diagnosis of mold infection were evaluated. Images were acquired with 16, 64, and 128 row CT scanners using a tube voltage of $80-120 \mathrm{kV}$ and automatic tube current modulation (with reference mAs between 80 and $120 \mathrm{mAs}$ or similar noise levels). The slice reconstruction thickness was 1 or $2 \mathrm{~mm}$. IV contrast agent was applied in 36 of the 85 CT scans (e. g., for additional assessment of pulmonary embolism or empyema). The following CT models were used (the number of patients per scanner is indicated): Somatom Definition Flash $(n=28)$, Somatom Definition AS+ $(n=13)$, Somatom Definition Edge $(n=13)$, Somatom Sensation $64(n=6)$ by Siemens (Siemens Healthineers, Erlangen, Germany); GE Light Speed VCT $(n=12)$, GE Discovery STE $(n=6)$, GE Bright Speed $S(n=2)$ by General Electrics (GE, Milwaukee, WI, USA); Toshiba Aquillion $(n=3)$ by Canon (Canon Medical Systems Corporation, Otawara, Tochigi, Japan) and Philipps Brilliance $64,(n=2)$ by Philips (Philips, Best, The Netherlands). Images were anonymized and randomized before radiological reading. All rating was done on a digital Picture Archiving System (PACS) workstation. All cases were read centrally by two independent teams of radiologists, with each team consisting of a resident and a senior consultant thoracic radiologist with five and eight years of experience, respectively. Discordant results between the two rating teams were resolved by consensus read-out amongst the four radiologists. The readers were blinded to the patient demographics and clinical outcomes. Lung patterns were classified as follows: consolidation ( \pm bronchogram, \pm enhancement, \pm halo sign, wedge-shaped peripheral infarction); ground glass opacity (diffuse, patchy or mosaic); nodules ( $<5 \mathrm{~mm}, 5-10 \mathrm{~mm},>10 \mathrm{~mm}$, halo sign, lobulated, spiculated, cavitary \pm air crescent sign, calcified); interstitial patterns (reticulation, centrilobular, perilymphatic nodules); and bronchial findings (wall thickening, bronchiectasis, tree-in-bud, bullae, and cysts (see table in appendix)) [19]. Each of the five lobes was analyzed separately. The axial distribution was noted as central predominant (inner $1 / 3$ of the lungs), peripheral predominant (outer 2/3 of the lungs), or diffuse and \pm subpleural sparing. Angioinvasivity was defined as the presence of infarction and the halo or crescent sign. The probability of invasive mold infection was estimated 
by the readers as $<25 \%,<50 \%,<75 \%$, and over $75 \%$ according to the presence of nodules with the halo sign in the upper lobes and the previously mentioned signs of angioinvasivity. Furthermore, additional findings such as lymphadenopathy (mediastinal or hilar nodes $>1 \mathrm{~cm}$ ) and pleural effusions were noted.

\section{Clinical findings/diagnostic workup}

Proof of invasive pulmonary fungus was established based on the identification of fungal hyphae from BAL, needle aspiration, or in biopsy specimen. Probable IPA was established with a combination of one host factor $(<500$ neutrophils for more than 10 days, persistent fever above $38^{\circ} \mathrm{C}$, graft-vs.-host disease or use of steroids for longer than 3 weeks) and one microbiological criterion (i. e., mold detection in culture from BAL, sputum, or sinus aspirate specimens) and one major (or two minor) clinical criteria [9]. The major factors included CT finding of halo sign, air crescent sign, cavity in consolidation, whereas minor factors were the presence of cough, chest pain, hemoptysis, dyspnea, pleural rub, pleural effusion, or consolidation [9]. Neutropenic patients with invasive fungal infections were defined as those patients who received chemotherapy for acute leukemia, lymphoma, or aplastic anemia while having an absolute neutrophil count $<500$ cells $/ \mathrm{mm}^{3}$ within 30 days prior to diagnosis of IFI [10].

The outcome after 6 weeks was classified according to Herbrecht et al. [20] and additional categories were implemented (death due to invasive pulmonary fungus or other cause). Complete response was defined by the resolution of all clinical signs and symptoms and more than 90 percent of the lesions due to invasive aspergillosis that were visible on CT. Partial response was defined by clinical improvement and $>50 \%$ improvement in findings on radiology. Stable response was defined by the absence of change from baseline or an improvement of $<50 \%$. Failure of therapy was defined by worsening disease based on imaging or fatal outcome. For the statistical analysis, the patients were divided into four groups: 1) positive outcome (complete, partial, and stable response); 2) progressive disease 3 ) death due to causes other than infection; and 4) death due to infection.

\section{Statistical methods}

IPA and NAIMI were pooled together into the group of invasive Aspergillus and non-Aspergillus infections (=IANA). The prevalence and distribution of the chest CT patterns of IANA, PCP, and Cryptococcus were analyzed individually. For these three fungal agents, a separate pattern analysis was performed according to the patient's immune status. In addition, patterns were cross-referenced with a positive versus a negative outcome (outcome 1 vs. 2-4). As PCP and Cryptococcus always had a favorable outcome, their outcome was not subdivided. A separate pattern analysis was performed for all included IANA cases versus only the proven IANA cases (probable infections were excluded). The Chi square test or Fisher exact test was used when appropriate. The pattern and distribution were analyzed per patient and per lobe. A Bonferroni correction was made according to the number of patterns examined. For the analysis among the different subgroups of immune status, a correction factor of 3 was applied for the main patterns (consolidations, GGO, and nodules). All tests of significance were two-tailed, and a p-val- ue of $<0.05$ was considered to indicate statistical significance. Calculations were performed with MedCalc version 16.4.3 (MedCalc Software, Ostend, Belgium).

\section{Results}

\section{Patient characteristics}

The mean age of the 85 included patients (54 males) was $60 \pm$ 15 years (range: 20 to 82 years). The total number of patients with IANA, PCP, and Cryptococcus was 60, 22, and 3, respectively $(\triangleright$ Table 1). Immune status categorization revealed the following numbers per group 1$)$ neutropenia $(n=44), 2)$ steroid therapy ( $n=36), 3$ ) OTR ( $n=11,7$ kidney and 4 lung). 4) other diseases $(n=17)$.

\section{Stratified according to immune status - per patient}

\section{Consolidations}

Overall, the consolidation pattern was seen in $65.9 \%$ of cases in the neutropenic group, followed by the steroid group with $44.4 \%$, OTR with $27.3 \%$, and the group of various diseases with $52.9 \%$ ( $\triangleright$ Fig. 5). OTR vs. neutropenia was significant with a $\mathrm{p}$-value of 0.045. In patients under steroid therapy, patients suffering from PCP demonstrated a significantly lower incidence of consolidations (11.1\%) compared to IANA patients $(57.7 \%$, p-value $=0.045)$.

\section{GGO}

There was no significant difference in GGO incidence among the various groups of immune status (54.5-76.5\%, > Fig. 5). However, patients with PCP demonstrated generally more GGO than patients witch IANA in the neutropenic group: $100 \%$ vs. $55.6 \%$ ( $p$-value $=0.049)$.

\section{Nodules}

There was a high incidence of pulmonary nodules. Each immune status group showed at least one nodule in $>72.7 \%$ of the patients. In the neutropenia group, the invasive fungi patients had significantly more nodules (94.4\%) compared to the PCP group ( $50.0 \%, p=0.002)$. In the other groups, the results were similar but did not reach statistical significance. Cavernous nodules were found in $11.4 \%, 19.4 \%, 18.2 \%$, and $23.5 \%$ of the patients in the neutropenia, steroid, OTR, and various diseases groups, respectively $(p>0.05)$. Generally, the frequency of large cavernous nodules was higher at $7.3 \%$. Intermediate and small cavernous nodules were present in only $3.3 \%$ and $2.3 \%$, respectively (appendix table). The typical crescent sign in angioinvasive fungal pneumonia was only found in 2 IANA patients (3.3\%), and both had a favorable outcome. The halo sign was observed in $56.7 \%, 27.3 \%$, and $0 \%$ of cases of IANA, PCP, and CRY, respectively.

\section{Lymph nodes, pleural effusion}

The incidence of lymphadenopathy was generally low (<18\%) among the different groups. Also, the incidence of pleural effusion was only $<25 \%$. Both findings did not differ significantly 
- Table 1 Clinical findings of the study populations.

- Tab. 1 Klinische Befunde der Studienpopulation.

\begin{tabular}{|c|c|c|c|c|c|}
\hline & \multirow[b]{2}{*}{ all } & \multicolumn{2}{|l|}{ IANA } & \multirow[b]{2}{*}{ PCP } & \multirow[b]{2}{*}{ CRY } \\
\hline & & IPA & NAIMI & & \\
\hline $\begin{array}{l}\text { age: mean } \\
\text { [range] }\end{array}$ & $\begin{array}{l}59.1 \\
{[18.3-89.3]}\end{array}$ & $\begin{array}{l}60.8 \\
{[18.3-89.3]}\end{array}$ & $\begin{array}{l}49.8 \\
{[20.3-61.1]}\end{array}$ & $\begin{array}{l}58.2 \\
{[22.2-89.3]}\end{array}$ & $\begin{array}{l}47.2 \\
{[42.1-53.7]}\end{array}$ \\
\hline $\mathrm{n}$, total & 85 & 53 & 7 & 22 & 3 \\
\hline $\mathrm{n}$, male & 54 & 33 & 3 & 16 & 2 \\
\hline $\mathrm{n}$, female & 31 & 20 & 4 & 6 & 1 \\
\hline \multicolumn{6}{|l|}{ risk factors for IFI } \\
\hline 1) neutropenia & 44 & 29 & 7 & 8 & 0 \\
\hline - AML & 14 & 9 & 3 & 2 & 0 \\
\hline - ALL & 4 & 3 & 1 & 0 & 0 \\
\hline - CLL & 8 & 4 & 1 & 3 & 0 \\
\hline - NHL & 5 & 3 & 1 & 1 & 0 \\
\hline - other & 13 & 10 & 1 & 2 & 0 \\
\hline - (chemotherapy & 26 & 20 & 5 & 1 & 0) \\
\hline 2) steroids & 36 & 24 & 2 & 9 & 1 \\
\hline 3) solid organ transplant & 11 & 7 & 0 & 3 & 1 \\
\hline 4) other & 17 & 9 & 0 & 6 & 2 \\
\hline \multicolumn{6}{|l|}{ diagnostic certainty } \\
\hline IFI diagnosis proven & 67 & 35 & 7 & 22 & 3 \\
\hline IFI diagnosis probable & 18 & 18 & 0 & 0 & 0 \\
\hline no specific fungal therapy & 61 & 36 & 2 & 20 & 3 \\
\hline specific fungal therapy & 24 & 17 & 5 & 2 & 0 \\
\hline fluconazole & 11 & 11 & 0 & 0 & 0 \\
\hline voriconazole & 3 & 2 & 1 & 0 & 0 \\
\hline posaconazole & 8 & 3 & 4 & 1 & 0 \\
\hline caspofungin & 1 & 1 & 0 & 0 & 0 \\
\hline bactrim forte & 1 & 0 & 0 & 1 & 0 \\
\hline
\end{tabular}

among the groups. Detailed results for all imaging patterns are demonstrated in the appendix table stratified by infective agent and lobar location.

\section{Stratified according to immune status - per lobe}

There was no significant difference among the immune status groups regarding lobe predilection ( $\triangleright$ Table 2 ). The signature sign for invasive pulmonary fungal infection was the solid nodule with the halo sign. In general, this nodule was found more often in the upper lobes $(p<0.001)$. The lower incidence for this nodule for organ transplant recipients is not significant.

\section{Stratified according to infective agent}

Lung pattern frequency in IANA patients

IANA patients demonstrated significantly more nodules (93.3\%) than GGO (58.3\%) and consolidations (56.7\%) $(p<0.001)$. Solid nodules with the halo sign and ground glass nodules (GGN) were more common than cavitary nodules ( $\triangleright$ Fig. 2, 3): $32.7 \%, 28.3 \%$, and $25.3 \%$, versus $9.0 \%(p<0.001)$. In patients with IANA infection, $4.7 \%$ of the lung lobes showed a wedge-shaped peripheral consolidation (infarction, Fig. 4 ) compared to $0 \%$ in PCP $(p=0.1)$. 
- Table 2 Prevalence of solid nodules with positive halo sign per lobe.

- Tab.2 Prävalenz von soliden Knoten mit positivem Halo-Zeichen pro Lappen.

\begin{tabular}{|l|l|l|l|r|}
\hline immune status & neutropenia & steroids & organ TX & other \\
\hline right upper lobe & $43.2 \%$ & $33.3 \%$ & $18.2 \%$ & $23.5 \%$ \\
\hline middle lobe & $22.7 \%$ & $22.2 \%$ & $9.1 \%$ & $5.9 \%$ \\
\hline right lower lobe & $29.5 \%$ & $19.4 \%$ & $9.1 \%$ & $5.9 \%$ \\
\hline left upper lobe & $36.4 \%$ & $36.1 \%$ & $9.1 \%$ & $17.6 \%$ \\
\hline left lower lobe & $22.7 \%$ & $22.2 \%$ & $9.1 \%$ & $5.9 \%$ \\
\hline
\end{tabular}

Prevalence is demonstrated as percentage per lobe and per immune status.
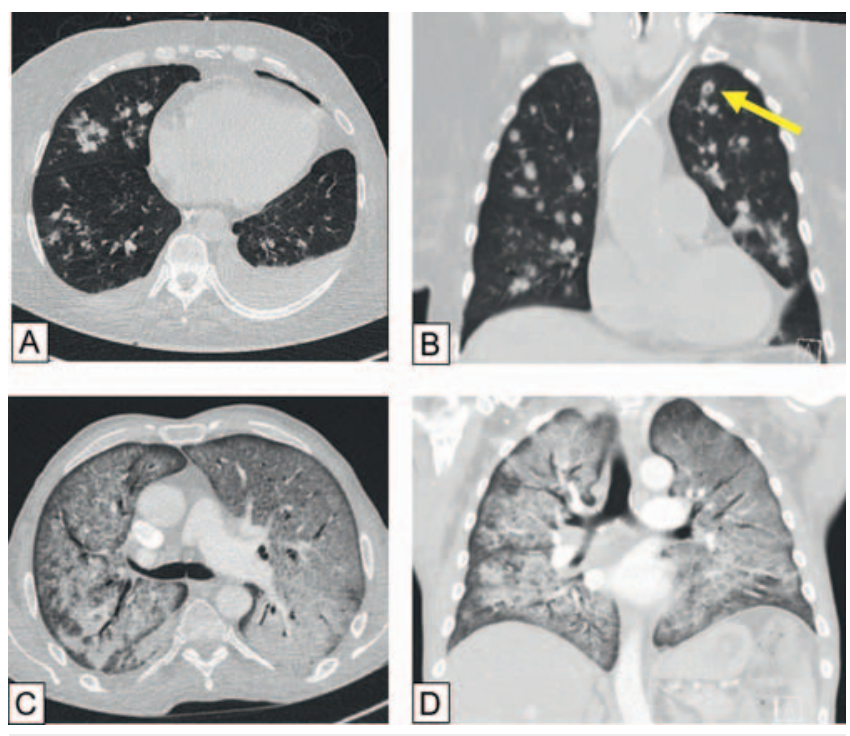

- Fig. 2 Patient examples of invasive Aspergillosis and Pneumocystis jiroveci. A 66-year-old female patient with invasive Aspergillosis is illustrated in the top row A, B. Multiple solid, ground glass, and cavernous nodules (arrow) are visible. She died due to the mold infection. In the lower row C, D, CT images of a 58-year-old male patient with Pneumocystis jiroveci (PCP) infection are shown. The subpleural sparing of the mainly ground glass changes was only found in PCP cases.

Abb. 2 Invasive Aspergillose und Pneumocystis-jiroveci-Infektion. Die obere Reihe A, B zeigt Bilder einer 66-jährigen Frau mit invasiver Aspergillose. Multiple Knoten, teils solide, teils milchglasartig, oder auch eingeschmolzene Knoten (Pfeil) sind sichtbar. Sie starb an den Folgen der Pilzinfektion. In der unteren Reihe C, D werden CT-Bilder eines 58-jährigen männlichen Patienten mit Pneumocystis-jiroveci (PCP) -Infektion gezeigt. Die subpleuralen Aussparungen der milchglasartigen Lungenverdichtungen waren nur bei PCP-Patienten zu sehen.

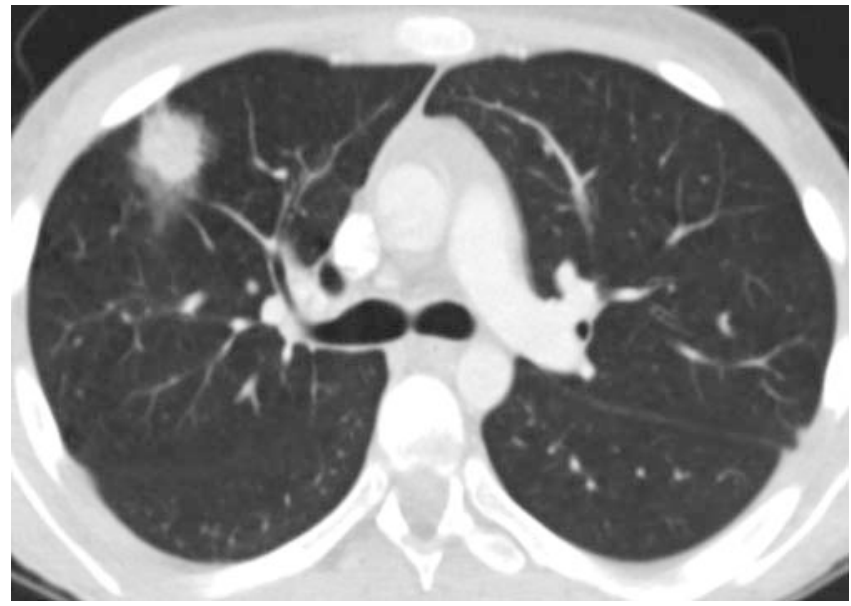

- Fig. 3 59-year-old female patient suffering from chronic lymphatic leukemia and Mucor pneumonia. Axial CT slice showing a single nodule with a halo sign in the right upper lobe.

- Abb.3 59-jährige Patientin mit chronisch lymphatischer Leukämie und Mucor-Pneumonie. Die axiale CT-Schicht zeigt einen einzelnen soliden Pilzknoten mit peripherem Milchglassaum (Halo-Zeichen) im rechten Oberlappen.

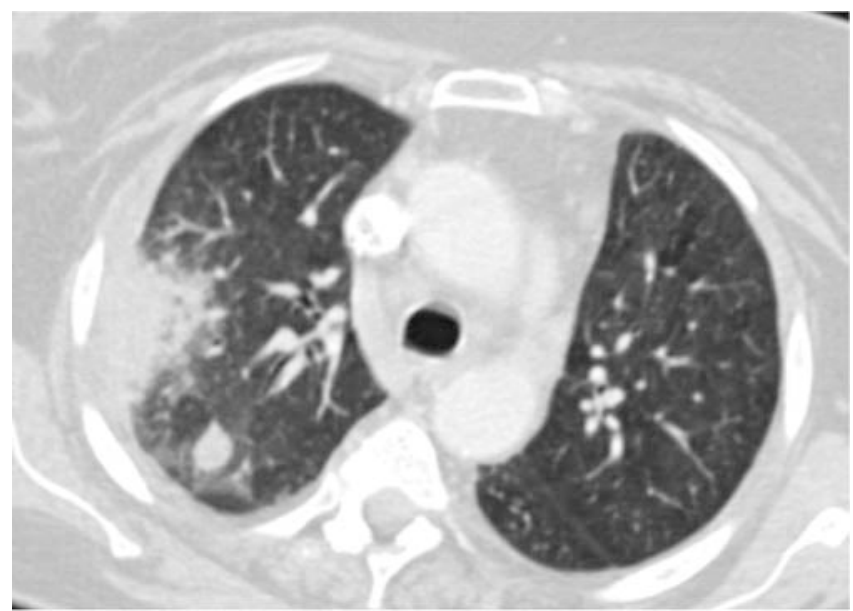

- Fig. 4 Angioinvasive Aspergillus infection of the lung in a patient with acute myeloid leukemia. The right upper lobe demonstrates a hemorrhagic peripheral infarction (wedge shape) and a posterior nodule with a halo sign due to invasion of the pulmonary vessels.

- Abb.4 Angioinvasive Aspergillus-Pneumonie bei akuter myeloischer Leukämie. Dreieckiger peripherer Lungeninfarkt und dorsaler Knoten mit Halo-Zeichen, verursacht durch die Gefäßinfiltration der Pilze.

\section{Lung pattern frequency in PCP patients}

Patients with PCP showed GGO in $95.5 \%$ of cases ( $\triangleright$ Fig. 2 ), nodules in $59.1 \%$, and consolidations in $45.5 \%$ ( $<<0.004)$. GGO was thus present significantly more often in patients with $\mathrm{PCP}$ compared to IANA and CRY (95.5\%, 58.3\%, and 33.3\%, respectively, $\mathrm{p}<0.009)$. Subpleural sparing was found only in patients with PCP (22.7\%, > Fig. 2). 


\begin{tabular}{|c|c|c|c|c|c|c|c|c|c|c|c|c|}
\hline Patterns & Consolid & ation & & & GGO & & & & Nodules & & & \\
\hline Immune status & 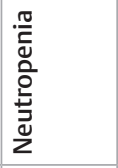 & 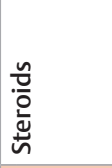 & 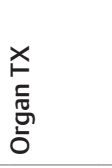 & 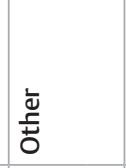 & 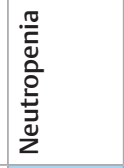 & 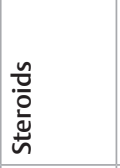 & 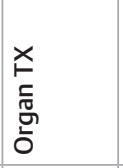 & 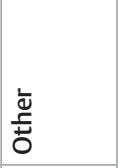 & 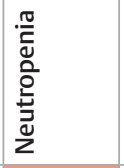 & 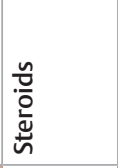 & 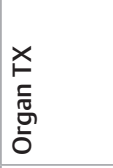 & 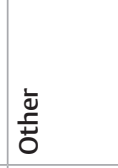 \\
\hline IA/NAIMI & $66.7 \%$ & $57.7 \%$ & $42.9 \%$ & $33.3 \%$ & $55.6 \%$ & $57.7 \%$ & $42.9 \%$ & $66.7 \%$ & $94.4 \%$ & $88.5 \%$ & $85.7 \%$ & $88.9 \%$ \\
\hline PCP & $62.5 \%$ & $11.1 \%$ & $0.0 \%$ & $83.3 \%$ & $100.0 \%$ & $88.9 \%$ & $100.0 \%$ & $100.0 \%$ & $50.0 \%$ & $55.6 \%$ & $33.3 \%$ & $66.7 \%$ \\
\hline Cryptococcosis & $\mathrm{N} / \mathrm{A}$ & $0.0 \%$ & $0.0 \%$ & $50.0 \%$ & $\mathrm{~N} / \mathrm{A}$ & $0.0 \%$ & $0.0 \%$ & $50.0 \%$ & $\mathrm{~N} / \mathrm{A}$ & $100.0 \%$ & $100.0 \%$ & $100.0 \%$ \\
\hline Total & $65.9 \%$ & $44.4 \%$ & $27.3 \%$ & $52.9 \%$ & $63.6 \%$ & $63.9 \%$ & $54.5 \%$ & $76.5 \%$ & $86.4 \%$ & $80.6 \%$ & $72.7 \%$ & $82.4 \%$ \\
\hline p-value & 0.045 & 0.045 & 0.049 & $0.002>0$ & & & & & & & & \\
\hline
\end{tabular}

- Fig. 5 Prevalence of radiological patterns.

- Abb. 5 Prävalenz der radiologischen Muster.

\section{Lung pattern frequency in CRY patients}

All CRY patients demonstrated nodules, while $33 \%$ had consolidations and $33 \%$ had GGO (nodules vs. consolidations/GGO: $\mathrm{p}=0.083)$.

\section{Pattern prevalence according to the clinical outcome (IANA patients only)}

Patients who died from the IANA infection showed GGO in $83.3 \%$ of the cases (corresponding to a $31.6 \%$ higher prevalence than patients with a positive outcome; $p$-value $=0.44$ ), and a diffuse pattern distribution was more frequent (in $33.3 \%$ ) compared to patients with positive outcomes (in $0 \%, p=0.005$ ). In a per lobe analysis, we found that IANA patients with negative outcomes (progression or death) demonstrated significantly more nodules with the halo sign. $42.5 \%$ of the lobes were affected compared to $15.9 \%$ of the lobes in patients with a positive outcome $(p<0.0001)$. Patients with a negative outcome demonstrated especially smaller nodules with the halo sign. Small nodules $(<5 \mathrm{~mm})$, intermediate nodules $(5-10 \mathrm{~mm})$, and macronodules (>10 mm) with the halo sign affected $20.8 \%, 19.2 \%$, and $15.8 \%$ of the lobes in patients with a negative outcome compared to $6.9 \%, 5.5 \%$ and $8.3 \%$ of the lobes in patients with a positive outcome ( $p=0.007,0.005$ and 0.62$)$. Patients who died from fungal infection demonstrated the highest prevalence of intermediate nodules with the halo sign: $26.7 \%$ ( $p=0.002$ compared to positive outcomes). Furthermore, patients with positive outcomes showed more pulmonary infarctions (peripheral, wedge-shaped consolidations) than patients with negative outcomes $(8.3 \%$ vs. $0.8 \%, p=0.0466)$.

The frequencies for the presence of each lung pattern per patient are shown in $>$ Fig. 6 and per lobe in $>$ Fig. 7 .

\section{Angioinvasivity, probability of fungal infection, and rare patterns}

The probability of fungal pneumonia estimated by the reading radiologists based on previously described imaging criteria was observed with equal distribution in $26.4 \%, 26.4 \%, 25.3 \%$ and $21.9 \%$ of patients in the neutropenia, steroid, OTR, and various diseases groups, respectively, although signs of angioinvasivity were found in $31.0 \%$. Overall, the radiologists judged the probability of fungal infection in the IANA patients as high (>50\%) and for the PCP and CRY cases as low $(<50 \%, p=0.023)$. Subpleural sparing, solitary nodules, or the crescent sign was seen in $5.75 \%, 10.34 \%$, and $0.66 \%$ of the lobes, respectively. Other observed lung patterns that are not typically known for fungal infections were reticulation, bronchiectasis, and centrilobular bullae in $17.93 \%, 11.26 \%$ and $6.90 \%$, respectively, per lobe.

\section{Distribution within the lungs}

There was a trend for fungal infections affecting the upper lobes more than the lower lobes $(p=0.0852)$. The following patterns demonstrated a significantly higher involvement of the upper lobes in IANA patients: mosaic GGO, nodules with halo sign $(>10 \mathrm{~mm})$, and cavitary nodules (>10 mm) ( $>$ Fig. 7). We observed fungal lung changes significantly more often in the periphery (central vs. peripheral predominant, $p=0.0035$ ).

\section{CT pattern dependency on the fungus test confidence levels (all versus proven IANA infections)}

The prevalence of consolidations, GGO, and nodules for all IANA cases (proven and probable) was $56.7 \%, 58.3 \%$, and $93.3 \%$, respectively, and dropped insignificantly to $55.8 \%, 48.1 \%$, and $86.5 \%$, respectively, for the proven infections only (all p-values $>0.285$ ). Detailed data regarding prevalence and dependencies on immune status are given in $>$ Table 3. Also, the per lobe analysis and the results for the different outcomes did not demonstrate differences in $\mathrm{CT}$ pattern prevalence for different test confidence levels. 


\begin{tabular}{|c|c|c|c|c|c|c|c|c|}
\hline FUNGUS & \multicolumn{2}{|c|}{ Follow-up after 6 weeks } & $\mathrm{n}$ & Consolidation & GGO & Nodules & LN & PE \\
\hline \multirow[t]{7}{*}{ IPA/NAIMI } & \multicolumn{2}{|c|}{ a) Positive response (incl. stable) } & 29 & $48.3 \%$ & $51.7 \%$ & $89.7 \%$ & $3.4 \%$ & $20.7 \%$ \\
\hline & \multicolumn{2}{|c|}{ b) All progressive c, $\mathrm{d}$, e } & (24) & $62.5 \%$ & $58.3 \%$ & $95.8 \%$ & $4.2 \%$ & $29.2 \%$ \\
\hline & \multicolumn{2}{|c|}{ c) Progressive } & 4 & $75.0 \%$ & $25.0 \%$ & $100.0 \%$ & $0.0 \%$ & $0.0 \%$ \\
\hline & \multicolumn{2}{|c|}{ d) Death due to other cause } & 14 & $64.3 \%$ & $57.1 \%$ & $100.0 \%$ & $0.0 \%$ & $42.9 \%$ \\
\hline & \multicolumn{2}{|c|}{ e) Death due to IFI } & 6 & $50.0 \%$ & $83.3 \%$ & $83.3 \%$ & $16.7 \%$ & $16.7 \%$ \\
\hline & \multicolumn{2}{|c|}{ f) No follow-up } & 7 & $71.4 \%$ & $85.7 \%$ & $100.0 \%$ & $14.3 \%$ & $42.9 \%$ \\
\hline & \multicolumn{2}{|c|}{ g) All a-f } & 60 & $56.7 \%$ & $58.3 \%$ & $93.3 \%$ & $5.0 \%$ & $26.7 \%$ \\
\hline PCP & \multicolumn{2}{|c|}{ All with positive response } & 22 & $45.5 \%$ & $95.5 \%$ & $59.1 \%$ & $40.9 \%$ & $13.6 \%$ \\
\hline \multirow[t]{2}{*}{ CRY } & \multicolumn{2}{|c|}{ All with positive response } & 3 & $33.3 \%$ & $33.3 \%$ & $100.0 \%$ & $0.0 \%$ & $0.0 \%$ \\
\hline & \multicolumn{2}{|c|}{ p-value map } & & & & & & \\
\hline IPA/NAIMI a) & vs. & IPA/NAIMI b) & & 1.000 & 1.000 & 1.000 & 1.000 & 1.000 \\
\hline IPA/NAIMI a) & vs. & IPA/NAIMI e) & & 1.000 & 0.741 & 1.000 & 0.951 & 1.000 \\
\hline PCP & vs. & IPA/NAIMI (all, g) & & 1.000 & 0.005 & 0.001 & $<0.001$ & 0.996 \\
\hline CRY & vs. & PCP & & 1.000 & 0.008 & 0.792 & 0.792 & 1.000 \\
\hline CRY & vs. & IPA/NAIMI (all, g) & & 1.000 & 1.000 & 1.000 & 1.000 & 1.000 \\
\hline
\end{tabular}

Patients with IPA/NAIMI are grouped based on their outcome after 6 weeks $(\mathrm{a}-\mathrm{g})$.

Bonferroni correction applied. Significant differences $(p<0.05)$ are highlighted in bold font.

$\mathrm{GGO}$ = ground glass opacification, $\mathrm{LN}$ = lymph nodes; $\mathrm{PE}$ = pleural effusion; IPA = invasive pulmonary aspergillosis; NAIMI = non-Aspergillus invasive mold infection; $\mathrm{PCP}=$ pneumocystis jirovecii pneumonia; $\mathrm{CRY}=$ Cryptococcus; IFI = invasive fungal infection

- Fig. 6 Presence of each pattern in patients with IANA, PCP, and CRY in a per patient analysis.

- Abb. 6 Präsenz der jeweiligen CT-Muster in Patienten mit IANA, PCP und CRY in einer patientenbasierten Analyse.

\begin{tabular}{|c|c|c|c|c|c|c|c|c|c|c|c|c|c|c|c|c|c|c|c|}
\hline & \multicolumn{6}{|c|}{ IANA } & \multicolumn{6}{|c|}{ PCP } & \multicolumn{6}{|c|}{ CRY } \\
\hline & & \multicolumn{2}{|c|}{ UL } & \multicolumn{2}{|c|}{ LL } & \multicolumn{2}{|c|}{ ML } & \multicolumn{2}{|c|}{ UL } & \multicolumn{2}{|c|}{ LL } & \multicolumn{2}{|c|}{ ML } & \multicolumn{2}{|c|}{ UL } & \multicolumn{2}{|c|}{ LL } & \multicolumn{2}{|c|}{ ML } \\
\hline & & $\mathrm{n}$ & $\%$ & $\mathrm{n}$ & $\%$ & $n$ & $\%$ & $\mathrm{n}$ & $\%$ & $\mathrm{n}$ & $\%$ & $n$ & $\%$ & $\mathrm{n}$ & $\%$ & $\mathrm{n}$ & $\%$ & $\mathrm{n}$ & $\%$ \\
\hline \multirow{6}{*}{$\begin{array}{l}\text { Consoli- } \\
\text { dation }\end{array}$} & Any consolidation & 29 & $38.2 \%$ & 34 & $44.7 \%$ & 13 & $17.1 \%$ & 13 & $36.1 \%$ & 16 & $44.4 \%$ & 7 & $19.4 \%$ & 1 & $33.3 \%$ & 2 & $66.7 \%$ & 0 & $0.0 \%$ \\
\hline & Only consolidation & 13 & $38.2 \%$ & 17 & $50.0 \%$ & 4 & $11.8 \%$ & 8 & $42.1 \%$ & 7 & $36.8 \%$ & 4 & $21.1 \%$ & 0 & $0.0 \%$ & 0 & $0.0 \%$ & 0 & $0.0 \%$ \\
\hline & $\begin{array}{l}\text { With broncho- } \\
\text { pneumogram }\end{array}$ & 9 & $42.9 \%$ & 9 & $42.9 \%$ & 3 & $14.3 \%$ & 3 & $37.5 \%$ & 4 & $50.0 \%$ & 1 & $12.5 \%$ & 0 & $0.0 \%$ & 0 & $0.0 \%$ & 0 & $0.0 \%$ \\
\hline & With peripheral GGO & 3 & $21.4 \%$ & 7 & $50.0 \%$ & 4 & $28.6 \%$ & 6 & $60.0 \%$ & 4 & $40.0 \%$ & 0 & $0.0 \%$ & 1 & $33.3 \%$ & 2 & $66.7 \%$ & 0 & $0.0 \%$ \\
\hline & With enhancement & 8 & $32.0 \%$ & 13 & $52.0 \%$ & 4 & $16.0 \%$ & 1 & $16.7 \%$ & 3 & $50.0 \%$ & 2 & $33.3 \%$ & 0 & $0.0 \%$ & 0 & $0.0 \%$ & 0 & $0.0 \%$ \\
\hline & $\begin{array}{l}\text { Wedge shape } \\
\text { (infarction) }\end{array}$ & 5 & $35.7 \%$ & 7 & $50.0 \%$ & 2 & $14.3 \%$ & 0 & $0.0 \%$ & 0 & $0.0 \%$ & 0 & $0.0 \%$ & 0 & $0.0 \%$ & 0 & $0.0 \%$ & 0 & $0.0 \%$ \\
\hline \multirow{4}{*}{$\begin{array}{l}\text { GGO = } \\
\text { ground } \\
\text { glass } \\
\text { opacity }\end{array}$} & Any GGO & 37 & $43.0 \%$ & 36 & $41.9 \%$ & 13 & $15.1 \%$ & 35 & $40.7 \%$ & 34 & $39.5 \%$ & 17 & $19.8 \%$ & 2 & $66.7 \%$ & 1 & $33.3 \%$ & 0 & $0.0 \%$ \\
\hline & Diffuse & 9 & $50.0 \%$ & 7 & $38.9 \%$ & 2 & $11.1 \%$ & 16 & $41.0 \%$ & 15 & $38.5 \%$ & 8 & $20.5 \%$ & 0 & $0.0 \%$ & 0 & $0.0 \%$ & 0 & $0.0 \%$ \\
\hline & Patchy & 24 & $41.4 \%$ & 26 & $44.8 \%$ & 8 & $13.8 \%$ & 17 & $38.6 \%$ & 19 & $43.2 \%$ & 8 & $18.2 \%$ & 2 & $66.7 \%$ & 1 & $33.3 \%$ & 0 & $0.0 \%$ \\
\hline & Mosaic & 5 & $41.7 \%$ & 4 & $33.3 \%$ & 3 & $25.0 \%$ & 5 & $55.6 \%$ & 3 & $33.3 \%$ & 1 & $11.1 \%$ & 0 & $0.0 \%$ & 0 & $0.0 \%$ & 0 & $0.0 \%$ \\
\hline \multirow[t]{5}{*}{ Nodules } & Any nodule (N) & 85 & $49.1 \%$ & 65 & $37.6 \%$ & 23 & $13.3 \%$ & 18 & $52.9 \%$ & 11 & $32.4 \%$ & 5 & $14.7 \%$ & 2 & $50.0 \%$ & 1 & $25.0 \%$ & 1 & $25.0 \%$ \\
\hline & GGN & 38 & $50.0 \%$ & 26 & $34.2 \%$ & 12 & $15.8 \%$ & 11 & $50.0 \%$ & 8 & $36.4 \%$ & 3 & $13.6 \%$ & 0 & $0.0 \%$ & 1 & $50.0 \%$ & 1 & $50.0 \%$ \\
\hline & $\mathrm{N}$ with halo sign & 44 & $51.8 \%$ & 29 & $34.1 \%$ & 12 & $14.1 \%$ & 6 & $60.0 \%$ & 3 & $30.0 \%$ & 1 & $10.0 \%$ & 0 & $0.0 \%$ & 0 & $0.0 \%$ & 0 & $0.0 \%$ \\
\hline & Solid N & 49 & $50.0 \%$ & 37 & $37.8 \%$ & 12 & $12.2 \%$ & 5 & $62.5 \%$ & 1 & $12.5 \%$ & 2 & $25.0 \%$ & 2 & $100.0 \%$ & 0 & $0.0 \%$ & 0 & $0.0 \%$ \\
\hline & Cavitary N & 18 & $66.7 \%$ & 6 & $22.2 \%$ & 3 & $11.1 \%$ & 0 & $0.0 \%$ & 0 & $0.0 \%$ & 0 & $0.0 \%$ & 0 & $0.0 \%$ & 0 & $0.0 \%$ & 0 & $0.0 \%$ \\
\hline
\end{tabular}

IANA = Invasive Aspergillosis and non-Aspergillus infection; $\mathrm{PCP}=$ Pneumocystis jirovecii Pneumonia; $C R Y=$ Cryptococcosis; $\mathrm{UL}=$ upper lobes; $\mathrm{LL}=$ lower lobes; $\mathrm{ML}=$ middle lobe; $\mathrm{n}=\mathrm{number} ;$ $\mathrm{GGO}=$ ground glass opacity; $\mathrm{GGN}=$ ground glass nodule; $\mathrm{N}=$ nodule

Fig. 7 Presence of each pattern in patients with IANA, PCP, and CRY is shown per lobe.

- Abb.7 Präsenz der verschiedenen Muster in Patienten mit IANA, PCP und CRY in einer lappenbasierten Analyse.

\section{Discussion}

The data from this multicenter study show that nodules, GGO, and consolidations are common CT findings in all mold infections. Thus, there was no sign that was unique for one specific patho- gen. However, nodules were more predominant in IANA and CRY and GGO was most often correlated with PCP. Solid nodules with the halo sign $<10 \mathrm{~mm}$ were associated with a worse outcome in our population. 


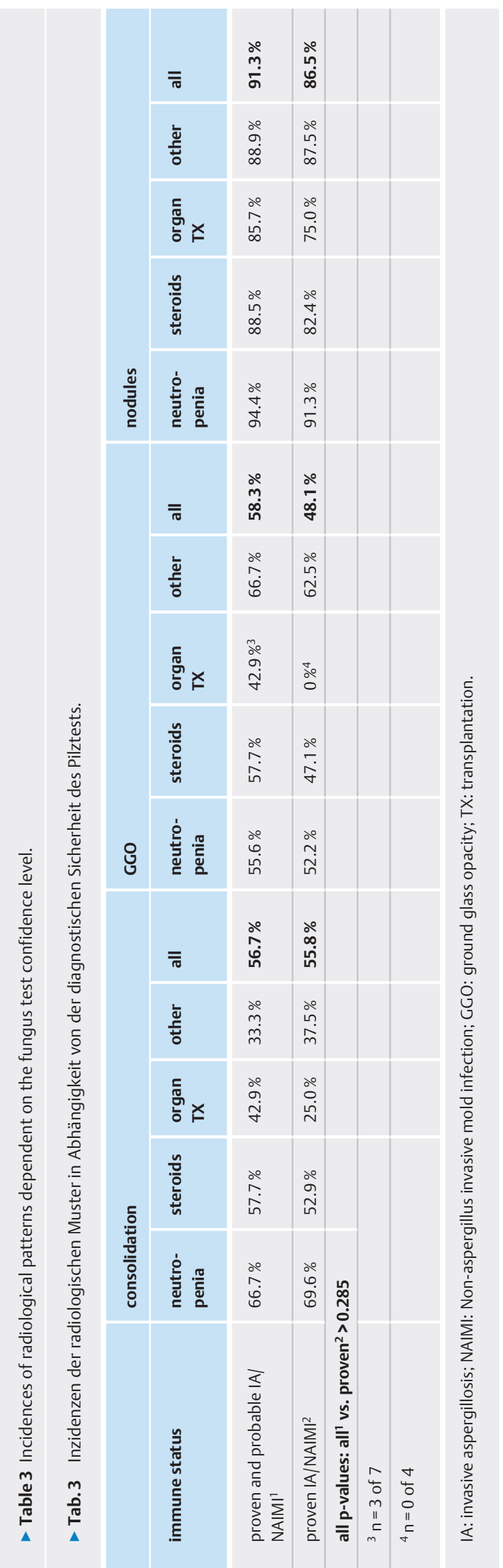

Our data are consistent with a study from Xu et al. who compared imaging findings in IPA patients with and without hematological malignancies [21]. While in non-hematological patients, the airway-invasive form, manifesting ground-glass opacity and consolidation or mass formation, was more common, while in patients with hematological malignancy, the angioinvasive form with macronodules (74.5\%) and halo signs (50\%) was more frequent. In the present study, the most common radiologic findings in patients with IANA were nodules (93\%). Nodular lesions were the most common finding on CT in other studies too, and their absence argues against the likelihood of IPA [22]. For example, nodules were seen in $74 \%$ of neutropenic patients in a study by Militio et al. [23]. For most types of nodules (GGN, solid nodules with the halo sign), we observed a higher frequency of small (approximately $20 \%$ ) and intermediate size (10\%) nodules than macronodules ( $2 \%)$. The only exceptions were cavernous nodules with the highest frequency of macronodules (7\%). This might be explained by: a) our definition of size criteria (macronodules were defined as nodules $>10 \mathrm{~mm}$, compared to other studies defining macronodules as > 3-5 mm); and b) our inclusion criteria, because we evaluated early CT scans within the first week of diagnosis, and it is known that nodule size increases during the first 10 days of infection [24].

Whereas it is widely acknowledged that the halo sign is seen frequently in patients with early-stage IPA, not all authors in the literature have reported the same high frequency [18]. In fact, the incidence of the halo sign among neutropenic patients with hematological malignancies has varied widely, ranging from $25 \%$ to $95 \%$ [8, 25-31]. The halo sign was observed in $56.7 \%, 27.3 \%$, and $0 \%$ of cases of IANA, CRY, and PCP, respectively. Although nonspecific, in severely neutropenic patients, the halo sign is highly suggestive of IFI [32, 33]. In addition, the halo sign appears to occur less frequently in patients without neutropenia who have pulmonary aspergillosis than in those with neutropenia, particularly when they are receiving corticosteroid therapy [34], according to our results ( $\triangleright$ Table 2 ).

After the initiation of antifungal therapy, fragments of infarcted lung may separate from the adjacent parenchyma (pulmonary sequestra), resulting in a cavity with an air crescent (air crescent sign) [32]. As this takes some time to develop in the course of aspergillosis [35], we only observed two cases of air crescent sign at this early CT exam time point. As the air crescent sign is a sign of healing $[28,35]$, it is not surprising that those two patients had a favorable outcome. Other CT findings described in the literature are pleura-based, wedge-shaped areas of consolidation [25, 36]. These findings correspond to hemorrhagic infarcts, and we observed them in the IANA group in up to $5 \%$ of cases.

We observed a significantly higher involvement of the upper lobes in IANA patients for mosaic GGO, nodules with the halo sign, and cavitary nodules. Similar findings were noted by $\mathrm{Xu}$ et al. [21]. In our study, the nodular pattern was registered significantly more often in the upper lobes. In contrast, Militio et al. showed an equal distribution between the different lobes of the lungs, with nodular lesions in $81 \%$ of the upper lobes, $81 \%$ of the lower lobes, and $63 \%$ of the middle lobe or lingula [23]. Similar to their study, we observed nodular lesions to be predominantly peripheral and multiple. 
Our findings suggest that certain radiologic findings such as infarctions are associated with a favorable outcome and others like GGO with a poor clinical outcome after 6 weeks. In contrast to the literature [37], we cannot confirm the favorable outcome in patients with the halo sign in our cohort. Nodules with the halo sign $(<1 \mathrm{~cm})$ were seen in $20 \%$ of patients who died due to the fungal infection and in $15 \%$ of patients with a negative outcome after 6 weeks as compared to $6 \%$ of patients with a positive outcome. Additionally, larger nodules with the halo sign were more frequent in patients with a negative outcome, but the difference was not significant. Park et al. [22] also suggested that macronodules and multiple infarct-shaped consolidations have prognostic implications in patients with IPA. In a study from singh et al., lung transplant recipients with IPA had better outcomes if nodular lesions were present [38].

Geltner et al. [39] have shown that the most common infectious agent in transplant recipients is Aspergillus fumigatus (67\%). This is in concordance with our results, which showed $65 \%$ of OTR patients with IANA, $27 \%$ with PCP and $9 \%$ with Cryptococcosis. Hekimoglu et al. [40] evaluated CT patterns in a group of 15 patients post-solid organ transplantation with proven diagnosis of invasive pulmonary aspergillosis. The most frequently observed patterns in their population were nodules and GGO which is in concordance with the results of our study as well as with data from Qin et al. [41]. However, Qin et al. observed nodules in $64 \%$ of cases and masses in $36 \%$.

Park et al. studied CT patterns in two patient groups and found similar findings in patients with neutropenia $(n=60)$ and non-neutropenic organ transplant recipients $(n=60)$ suffering from IPA [22]. In their study, consolidations or masses, halo signs, and an angioinvasive form were observed less often in non-neutropenic transplant recipients than in neutropenic patients $(56 \%$, $26 \%$ and $32 \%$ vs. $78 \%, 55 \%, 60 \%$ with $p=0.01, p=0.002$ and $p=0.003$, respectively). This is consistent with our observations, although our groups were a little different with consolidations, GGO, and nodules being present in $67 \%, 56 \%$, and $94 \%$ of IPA patients with neutropenia and in $43 \%, 43 \%$, and $86 \%$ of OTR patients. It is also known that cavitary formation only happens late in patients with neutropenia when aplasia is resolving. It is an early sign in patients undergoing steroid treatments. This was shown with $11 \%$ of neutropenic patients with cavernous nodule transformation and $19 \%$ of patients undergoing steroid therapy. Although the follow-up of such patients was not included in the scope of the present study, exemplary CT exams of some patients have shown the development of caverns as a sign of immune reconstitution.

Our study has several limitations. First, our population contains a mixed group of different fungal species (IANA $n=60, P C P n=22$, and $C R Y n=3$ ). This reflects the daily routine for clinical radiologists when they get a CT order with the suspicion of opportunistic infection but without confirmation or specific diagnosis. The reading radiologist thus needs to know the criteria for invasive infections to enable further diagnostic and therapeutic steps. Due to the strict Bonferroni correction of factor 33 (for all patterns) in the per lobe analysis, the differences had to be huge to be significant between different immune status groups. Some of the important patterns with marginally significant differences may have suffered from the inclusion of rather unimportant patterns. How- ever, for the sake of completeness, we preferred to include all patterns. Furthermore, due to the retrospective cross-sectional design of our study, potential confounders were not controlled and follow-up of imaging patterns was not within the scope of this study and can be investigated in the future.

Conclusion: Patients with IANA showed a higher prevalence of nodules and a lower prevalence of ground glass opacities than patients with PCP. All patients with PCP and CRY had a favorable outcome. In patients with IANA, nodules with the halo sign were associated with an adverse outcome. Patients with neutropenia generally showed more consolidations, but consolidations were not associated with an adverse outcome.

\section{CLINICAL RELEVANCE}

- Chest CT gives important clues for the clinical suspicion and early treatment of invasive mold pneumonia in immunocompromised patients

- This study with a systematic analysis of imaging patterns improves the understanding of CT patterns in invasive pulmonary mold infections.

- Smaller (<5 mm) and intermediate (5-10 mm) nodules with the halo sign were more often associated with a negative outcome in IANA patients.

\section{Funding sources}

This work was supported by the Fungal Infection Network of Switzerland (FUNGINOS).

\section{Conflict of Interest}

The authors declare that they have no conflict of interest.

\section{References}

[1] von Eiff M, Roos N, Schulten R et al. Pulmonary aspergillosis: early diagnosis improves survival. Respiration; international review of thoracic diseases 1995; 62: 341-347

[2] Mucha K, Foroncewicz B, Orlowski T et al. Atypical presentation of invasive pulmonary aspergillosis in a liver transplant recipient. Annals of transplantation 2013; 18: 238-242

[3] Yan C, Tan X, Wei Q et al. Lung MRI of invasive fungal infection at 3 Tesla: evaluation of five different pulse sequences and comparison with multidetector computed tomography (MDCT). European radiology 2015; 25 : 550-557

[4] Karthaus M, Buchheidt D. Invasive aspergillosis: new insights into disease, diagnostic and treatment. Current pharmaceutical design 2013; 19: 3569-3594

[5] Walsh T], Gamaletsou MN. Treatment of fungal disease in the setting of neutropenia. Hematology American Society of Hematology Education Program 2013; 2013: 423-427

[6] Lee H], Cho SY, Lee DG et al. Characteristics and risk factors for mortality of invasive non-Aspergillus mould infections in patients with haematologic diseases: A single-centre 7-year cohort study. Mycoses 2020; 63: 257264 
[7] Agrawal R, Yeldandi A, Savas H et al. Pulmonary Mucormycosis: Risk Factors, Radiologic Findings, and Pathologic Correlation. Radiographics 2020. doi:10.1148/rg.2020190156:190156

[8] Kuhlman JE, Fishman EK, Burch PA et al. Invasive pulmonary aspergillosis in acute leukemia. The contribution of CT to early diagnosis and aggressive management. Chest 1987; 92: 95-99

[9] Ascioglu S, Rex JH, de Pauw B et al. Defining opportunistic invasive fungal infections in immunocompromised patients with cancer and hematopoietic stem cell transplants: an international consensus. Clinical infectious diseases: an official publication of the Infectious Diseases Society of America 2002; 34: 7-14

[10] De Pauw B, Walsh T], Donnelly JP et al. Revised definitions of invasive fungal disease from the European Organization for Research and Treatment of Cancer/Invasive Fungal Infections Cooperative Group and the National Institute of Allergy and Infectious Diseases Mycoses Study Group (EORTC/MSG) Consensus Group. Clinical infectious diseases: an official publication of the Infectious Diseases Society of America 2008; 46: 1813-1821

[11] Ruhnke M, Behre G, Buchheidt D et al. Diagnosis of invasive fungal diseases in haematology and oncology: 2018 update of the recommendations of the infectious diseases working party of the German society for hematology and medical oncology (AGIHO). Mycoses 2018; 61: 796813

[12] Cornely OA, Alastruey-Izquierdo A, Arenz D et al. Global guideline for the diagnosis and management of mucormycosis: an initiative of the European Confederation of Medical Mycology in cooperation with the Mycoses Study Group Education and Research Consortium. The Lancet Infectious diseases 2019; 19: e405-e421

[13] Ullmann AJ, Aguado JM, Arikan-Akdagli S et al. Diagnosis and management of Aspergillus diseases: executive summary of the 2017 ESCMIDECMM-ERS guideline. Clinical microbiology and infection: the official publication of the European Society of Clinical Microbiology and Infectious Diseases 2018; 24 (Suppl. 1): e1-e38

[14] Lass-Florl C. How to make a fast diagnosis in invasive aspergillosis. Medical mycology 2019; 57: S155-S160

[15] Godet C, Elsendoorn A, Roblot F. Benefit of CT scanning for assessing pulmonary disease in the immunodepressed patient. Diagnostic and interventional imaging 2012; 93: 425-430

[16] Wang J, Zhang C, Lin J et al. Clinical diagnostic value of spiral CT in invasive pulmonary fungal infection. Experimental and therapeutic medicine 2019; 17: 4149-4153

[17] Legouge C, Caillot D, Chretien ML et al. The reversed halo sign: pathognomonic pattern of pulmonary mucormycosis in leukemic patients with neutropenia? Clinical infectious diseases: an official publication of the Infectious Diseases Society of America 2014; 58: 672-678

[18] Georgiadou SP, Sipsas NV, Marom EM et al. The diagnostic value of halo and reversed halo signs for invasive mold infections in compromised hosts. Clinical infectious diseases: an official publication of the Infectious Diseases Society of America 2011; 52: 1144-1155

[19] Hansell DM, Bankier AA, MacMahon H et al. Fleischner Society: glossary of terms for thoracic imaging. Radiology 2008; 246: 697-722

[20] Herbrecht R, Denning DW, Patterson TF et al. Voriconazole versus amphotericin B for primary therapy of invasive aspergillosis. The New England journal of medicine 2002; 347: 408-415

[21] Xu S, Qiu L, Liu W et al. Initial computed tomography findings of invasive pulmonary aspergillosis in non-hematological patients. Chinese medical journal 2012; 125: 2979-2985

[22] Park SY, Lim C, Lee SO et al. Computed tomography findings in invasive pulmonary aspergillosis in non-neutropenic transplant recipients and neutropenic patients, and their prognostic value. The Journal of infection 2011; 63: 447-456
[23] Milito MA, Kontoyiannis DP, Lewis RE et al. Influence of host immunosuppression on CT findings in invasive pulmonary aspergillosis. Medical mycology 2010; 48: 817-823

[24] Marom EM, Kontoyiannis DP. Imaging studies for diagnosing invasive fungal pneumonia in immunocompromised patients. Current opinion in infectious diseases 2011; 24: 309-314

[25] Kuhlman JE, Fishman EK, Siegelman SS. Invasive pulmonary aspergillosis in acute leukemia: characteristic findings on CT, the CT halo sign, and the role of CT in early diagnosis. Radiology 1985; 157: 611-614

[26] Bruno C, Minniti S, Vassanelli A et al. Comparison of CT features of Aspergillus and bacterial pneumonia in severely neutropenic patients. Journal of thoracic imaging 2007; 22: 160-165

[27] Kami M, Kishi Y, Hamaki T et al. The value of the chest computed tomography halo sign in the diagnosis of invasive pulmonary aspergillosis. An autopsy-based retrospective study of 48 patients. Mycoses 2002; 45 : 287-294

[28] Caillot D, Couaillier JF, Bernard A et al. Increasing volume and changing characteristics of invasive pulmonary aspergillosis on sequential thoracic computed tomography scans in patients with neutropenia. Journal of clinical oncology: official journal of the American Society of Clinical Oncology 2001; 19: 253-259

[29] Horger M, Einsele H, Schumacher $U$ et al. Invasive pulmonary aspergillosis: frequency and meaning of the "hypodense sign" on unenhanced CT. The British journal of radiology 2005; 78: 697-703

[30] Won H], Lee KS, Cheon JE et al. Invasive pulmonary aspergillosis: prediction at thin-section CT in patients with neutropenia-a prospective study. Radiology 1998; 208: 777-782

[31] Greene RE, Schlamm HT, Oestmann JW et al. Imaging findings in acute invasive pulmonary aspergillosis: clinical significance of the halo sign. Clinical infectious diseases: an official publication of the Infectious Diseases Society of America 2007; 44: 373-379

[32] Marchiori E, Zanetti G, Hochhegger B et al. Reversed halo sign on computed tomography: state-of-the-art review. Lung 2012; 190: 389-394

[33] Kawel N, Schorer GM, Desbiolles L et al. Discrimination between invasive pulmonary aspergillosis and pulmonary lymphoma using CT. European journal of radiology 2011; 77: 417-425

[34] Ostrosky-Zeichner L. Invasive mycoses: diagnostic challenges. The American journal of medicine 2012; 125: S14-S24

[35] Liss B, Vehreschild J], Bangard C et al. Our 2015 approach to invasive pulmonary aspergillosis. Mycoses 2015; 58: 375-382

[36] Franquet T, Müller NL, Giménez A et al. Spectrum of Pulmonary Aspergillosis: Histologic, Clinical, and Radiologic Findings. RadioGraphics 2001; 21: 825-837

[37] Verweij PE, van Die L, Donnelly JP. Halo sign and improved outcome. Clinical infectious diseases: an official publication of the Infectious Diseases Society of America 2007; 44: 1666-1667; author reply 16671668

[38] Singh N, Suarez JF, Avery R et al. Risk factors and outcomes in lung transplant recipients with nodular invasive pulmonary aspergillosis. The Journal of infection 2013; 67: 72-78

[39] Geltner C, Lass-Florl C. Invasive pulmonary Aspergillosis in organ transplants-Focus on lung transplants. Respiratory investigation 2016; 54 : $76-84$

[40] Hekimoglu K, Haberal M, Serifoglu I et al. Diagnostic Analysis of Computed Tomography Patterns in Patients With Invasive Pulmonary Aspergillosis After Solid-Organ Transplantation. Experimental and clinical transplantation: official journal of the Middle East Society for Organ Transplantation 2019; 17: 216-219

[41] Qin J, Fang Y, Dong Y et al. Radiological and clinical findings of 25 patients with invasive pulmonary aspergillosis: retrospective analysis of 2150 liver transplantation cases. The British journal of radiology 2012; 85: e429-e435 